\title{
What Can We Learn About the Processes of Regulation of Tuberculosis Medicines From the Experiences of Health Policy and System Actors in India, Tanzania, and Zambia?
}

\author{
Kabir Sheikh ${ }^{1^{*}}$, Mukund Uplekar ${ }^{2}$
}

\begin{abstract}
Background: The unregulated availability and irrational use of tuberculosis (TB) medicines is a major issue of public health concern globally. Governments of many low- and middle-income countries (LMICs) have committed to regulating the quality and availability of TB medicines, but with variable success. Regulation of TB medicines remains an intractable challenge in many settings, but the reasons for this are poorly understood. The objective of this paper is to elaborate processes of regulation of quality and availability of TB medicines in three LMICs - India, Tanzania, and Zambia - and to understand the factors that constrain and enable these processes.

Methods: We adopted the action-centred approach of policy implementation analysis that draws on the experiences of relevant policy and health system actors in order to understand regulatory processes. We drew on data from three case studies commissioned by the World Health Organization (WHO), on the regulation of TB medicines in India, Tanzania, and Zambia. Qualitative research methods were used, including in-depth interviews with 89 policy and health system actors and document review. Data were organized thematically into accounts of regulators' authority and capacity; extent of policy implementation; and efficiency, transparency, and accountability.

Results: In India, findings included the absence of a comprehensive policy framework for regulation of TB medicines, constraints of authority and capacity of regulators, and poor implementation of prescribing and dispensing norms in the majority private sector. Tanzania had a policy that restricted import, prescribing and dispensing of TB medicines to government operators. Zambia procured and dispensed TB medicines mainly through government services, albeit in the absence of a single policy for restriction of medicines. Three cross-cutting factors emerged as crucially influencing regulatory processes - political and stakeholder support for regulation, technical and human resource capacity of regulatory bodies, and the manner of private actors' influence on regulatory policy and implementation. Conclusion: Strengthening regulation to ensure the quality and availability of TB medicines in LMIC with emerging private markets may necessitate financial and technical inputs to upgrade regulatory bodies, as well as broader political and ethical actions to reorient and transform their current roles.

Keywords: Tuberculosis (TB), Regulation, Policy Process, Qualitative Research

Copyright: @ 2016 by Kerman University of Medical Sciences

Citation: Sheikh K, Uplekar M. What can we learn about the processes of regulation of tuberculosis medicines from the experiences of health policy and system actors in India, Tanzania, and Zambia? Int J Health Policy Manag. 2016;5(7):403-415. doi:10.15171/ijhpm.2016.30
\end{abstract}

Article History:

Received: 4 September 2015

Accepted: 3 March 2016

ePublished: 9 March 2016
*Correspondence to:

Kabir Sheikh

Email: kabir.sheikh@phfi.org

\section{Key Messages}

Implications for policy makers

- The following critical factors around regulation of tuberculosis (TB) medicines require attention in the three study countries, Tanzania, Zambia, and India, with lessons for other low- and middle-countries (LMICs): inadequate political support for regulatory functions, poor technical and human resource capacity of regulatory bodies, and private actors' influence on regulatory policy and implementation.

- Strengthening regulation to ensure the quality and availability of TB medicines in LMICs with emerging private markets may necessitate financial and technical inputs to upgrade regulatory bodies, and also political actions to reorient and strengthen their roles.

Implications for the public

The quality and availability of tuberculosis (TB) medicines are consequences of regulatory processes that are political, sometimes influenced by private interests, and often hidden from public eye. It is important that people demand that regulatory processes should be accountable, transparent, and in the public interest, and that we respect the roles of people working in regulatory organizations since they play an important function in society.

\section{Introduction}

The unregulated availability and irrational use of tuberculosis (TB) medicines is a major issue of public health concern globally. Governments of many low- and middle-income countries (LMICs) have committed to regulating the quality and availability of TB medicines, but with variable success. Regulation of TB medicines remains an intractable challenge in many settings, but the reasons for this are poorly understood. The objective of this paper is to elaborate processes of regulation of quality and availability of $\mathrm{TB}$ 
medicines in three LMICs - India, Tanzania, and Zambia and to understand the factors that influence and constrain these processes.

Regulation of essential medicines is a critical function of the state. It encompasses a range of legal, administrative, and technical interventions in the activities of the pharmaceutical sector, undertaken with the aims of ensuring drug safety, efficacy and quality in the interests of public health ${ }^{1}$ (see Figure 1). The regulation of the quality and availability of antimicrobials such as TB medicines is of particular importance in the developing world, given the persistence of high burden of TB in many countries, and the emergence of drug resistance fuelled by widespread inappropriate prescribing and dispensing practices.

Governments across the world adopt measures to regulate the quality and availability of medicines - these measures are enacted through networks of regulatory organizations, typically consisting of a central authority and regional or provincial branches. The authority and capacity of regulatory organizations to enact policies, and the actual implementation of those policies are essential for the effectiveness of regulatory policies ie, their ability to produce desired outcomes of high drug quality, availability in response to need, and appropriate utilization. In addition to being effective, regulatory policies must also be efficient, transparent and accountable.

Regulation of quality and availability of TB medicines involves multiple functions, including licencing individuals and premises, inspecting manufacturers and distributors, assessing products and monitoring drug quality. Figure 2 sequentially maps the different processes involved in making TB medicines available to users, and the different actors involved. According to this sequence, the availability of TB medicines can be seen as a composite of three processes: (1) production and procurement - either by importation, or from domestic manufacturers, (2) storage and distribution, and (3) prescribing and dispensing. The map pinpoints the levels at which regulatory actions are usually applied, and the actors operating at these different levels, and was hence useful in guiding the selection of respondents and in writing up the research.
Different LMICs have had differing experiences of regulating TB medicines, yet there is little literature on national and subnational processes of regulation. In some instances national bodies regulating drug quality have been reported to be barely functional, ${ }^{2}$ while further down the chain, public sector procurers often struggle with stock control and inventory management. ${ }^{3-5}$ Poor treatment practices and the high prevalence of over-the-counter (OTC) dispensing of TB medicines have been explained by the absence of laws in this area and, where they do exist, by inadequate government capacities for enforcement of regulatory norms., ${ }^{6,7}$ The literature insufficiently examines the factors that underlie these widespread failures of regulatory institutions, and their variable effectiveness in different settings - this paper addresses this gap in the literature.

The framework of regulation used in this study (Figure 1) is adapted from the World Health Organization's (WHO's) landmark reports on effective drug regulation from 1999 and 2002. ${ }^{1,8}$ The framework outlines (1) the different activities (production and procurement, stocking and distribution, dispensing and prescribing) that are targets of regulation of TB medicines, and (2) the essential elements of regulation (organizational authority and capacity; implementation; efficient and accountable processes) that are necessary for the achievement of relevant outcomes related to drug quality and availablilty.

\section{Methods}

We follow an "action-centred" approach to investigating regulatory policy and implementation, in which regulatory processes can be seen as involving interactions between groups of actors within social and organizational contexts, and at different levels of policy and implementation. ${ }^{9}$ This approach seeks to understand regulatory processes through the lens of the experiences and perspectives of these policy and health system actors, which is achieved by conducting qualitative research to access these experiences. ${ }^{10,11}$

We drew on data from case studies on the regulation of TB medicines in India, Tanzania, and Zambia commissioned by the WHO, and conducted by a team of researchers led by the lead author in the period from 2009-2011. ${ }^{12,13}$ These

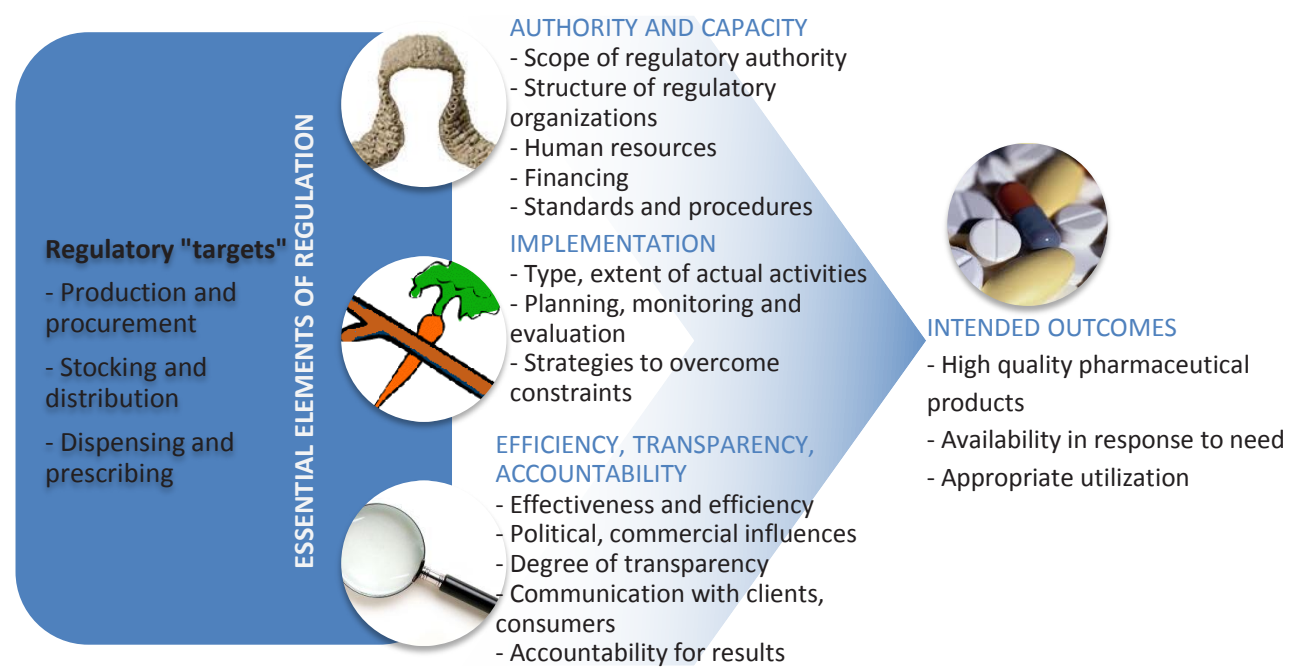

Figure 1. Framework for Regulation of Quality and Availability of Tuberculosis (TB) Medicines (Adapted From Ratanawijitrasin and Wondemagegnehu ${ }^{1}$ ). 


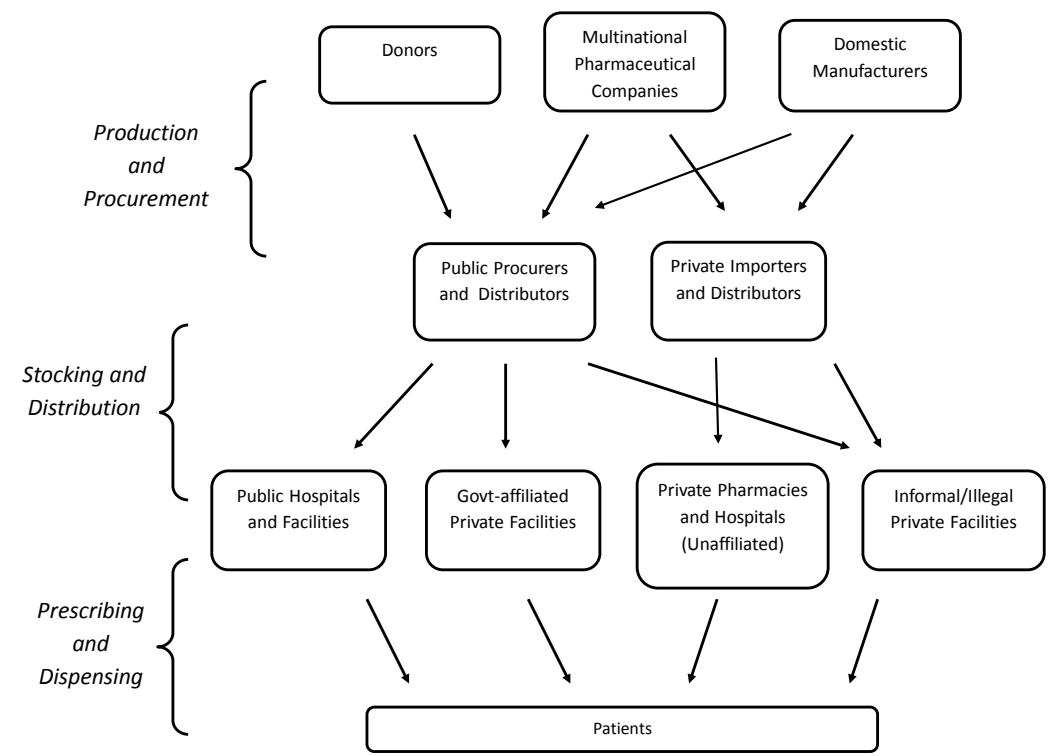

Figure 2. Targets of Regulatory Activities: Actors and Steps Involved in Making Tuberculosis (TB) Medicines Available.

country cases were selected purposefully as having variable contexts, with a view to gaining a wide range of observations and insights. The criteria for selection included (1) reported availability of TB drugs in private pharmacies (India: high; Tanzania and Zambia: low); (2) the size of the local private manufacturing and retail sectors for medicines (India: large; Tanzania and Zambia: smaller); and (3) geographical setting, ie, Asia and Africa.

For each case study, investigators conducted in-depth interviews ${ }^{14}$ with representatives of regulatory organizations and departments engaged in regulating the availability and quality of TB medicines, and with actors affected by these processes (Figure 2). A breakdown of study participants by country is presented in Table 1. Lists of study participants to be interviewed were drawn up purposefully, based on discussions with WHO country offices, National TB Programme (NTP) representatives and other key informants, with attention to ensuring maximum variability in the types of groups, and levels of administrative categories represented. ${ }^{15}$

Geographically, the participants were identified from within and around the capitals of the respective countries and/ or capitals of provinces or states, since typically regulatory institutions were located in these areas. In the case of India, due to the large size of the country, the research was conducted in the national capital Delhi, and also in two states selected on the basis of varying performance, in terms of standardized health indicators - Kerala (high performing) and Rajasthan (low performing). The interviews were supported and triangulated by review of relevant policy documentation. ${ }^{11}$ Numbers of participants, and an indicative list of types of participants interviewed and policy documents reviewed in each country is presented in Table 2.
The research team conducted structured interviews with study participants with the help of topic guides (see topic listings in Table 3), and written notes were taken during the interviews. Due to the diversity of institutional functions and roles, and different countries represented, the topic guides were adapted according to the respondent's specialised area of knowledge. Data from respondents' accounts and documentary sources were organized manually using word-processing software, and thematically analyzed using the "framework" approach of qualitative data analysis for applied policy research. ${ }^{16}$ Data were organized according to a thematic framework combining a priori themes reflecting the regulatory activities and processes outlined in Figure 1, as well as new and emergent themes arising from respondents accounts. The organized data were charted and data corresponding to different themes was extracted and written up as distinct case study reports. Cross-case themes were also identified, as part of the third, analytic stage of the framework approach. A priori, emergent and analytical themes were applied to the data and written up in the form of this paper.

Informed consent was obtained prior to conducting the interviews. All data were stored in encrypted format with restricted access, and care has been taken to ensure anonymity of all individuals cited in all research reports, including this article.

\section{Results}

In this section, we present findings from the three country case studies, respectively, around policy and health system actors' experiences of processes of regulation of quality and availability of TB medicines. Within each country case study, findings are organized according to key elements of

Table 1. Number of Interviews Conducted by Country $(n=89)$

\begin{tabular}{lll}
\hline Country & Number of Implementers/Regulators Interviewed & Number of Private Stakeholders/Actors Interviewed \\
\hline Tanzania & 14 & 9 \\
Zambia & 10 & 11 \\
India (Delhi, Kerala, Rajasthan) & 29 & 16 \\
Total & 53 & 36 \\
\hline
\end{tabular}


Table 2. Study Participants and Policy Documents Reviewed

\begin{tabular}{|c|c|c|}
\hline Implementers/Regulators & Private Stakeholders/Actors & Key Policy Documents \\
\hline $\begin{array}{l}\text { - } \quad \text { NTP officials and personnel } \\
\text { - } \quad \text { Health Ministry officials } \\
\text { - } \quad \text { Wrug regulatory authorities (national and provincial) } \\
\text { - } \quad \text { Administrators of provincial TB programmes, } \\
\text { facilities } \\
\text { Departments/agencies responsible for } \\
\text { pharmaceutical procurement, stocking and } \\
\text { dispensing } \\
\text { Professional regulatory bodies (national and } \\
\text { provincial) } \\
\text { Central laboratories and government production } \\
\text { units }\end{array}$ & $\begin{array}{ll}\text { - } & \text { Private hospital administrators } \\
\text { - } & \text { Private practitioners } \\
\text { - } & \text { Medical associations } \\
\text { - } & \text { Private pharmaceutical manufaturers and } \\
\text { - } & \text { Private pharmaceutical distributors and } \\
\text { - } & \text { Privatesalers } \\
\text { - } & \text { Government pharmacists and health } \\
\text { - } & \text { Prorkers }\end{array}$ & $\begin{array}{l}\text { Government TB programme } \\
\text { manuals, schemes and reports } \\
\text { Relevant laws and acts of the state } \\
\text { National health policy and plan } \\
\text { statements } \\
\text { Websites of relevant programmes } \\
\text { and authorities } \\
\text { Relevant expert and committee } \\
\text { reports on drug quality and rational } \\
\text { use }\end{array}$ \\
\hline
\end{tabular}

Abbreviations: WHO, World Health Organization; TB, tuberculosis; NTP, National TB Programme; NGOs, non-governmental organizations.

Table 3. List of Interview Topics ${ }^{a}$

\begin{tabular}{|c|c|}
\hline Implementers/Regulators & Private Stakeholders/Actors \\
\hline 1. Views on the problem of inappropriate use of TB medicines & $\begin{array}{l}\text { 1. Role of firm/organization in production/distribution/provision of TB } \\
\text { medicines }\end{array}$ \\
\hline 2. Policy or institutional stance on the problem & 2. Experiences of participating in these activities \\
\hline 3. Formal regulatory functions of institution & 3. Provisions for quality control in areas of work \\
\hline 4. Actual role of the institution vis-a-vis regulation of TB medicines - in detail & 4. Organizational stance vis-a-vis regulation of relevant activities \\
\hline $\begin{array}{l}\text { 5. Experiences of actual institutional processes relating to regulation of TB } \\
\text { medicines }\end{array}$ & 5. Views on the need for greater regulation of relevant activities \\
\hline $\begin{array}{l}\text { 6. Experiences of actual institutional processes relating to partnership with } \\
\text { private providers, where relevant }\end{array}$ & 6. Experiences of encountering regulatory processes if any - in detail \\
\hline 7. Role conflicts and overlaps with other institutions, if any & $\begin{array}{l}\text { 7. Experience of partnership with government TB programme (if } \\
\text { relevant) }\end{array}$ \\
\hline 8. Obstacles and concerns vis-a-vis the issue of regulation of TB medicines & $\begin{array}{l}\text { 8. Key obstacles and concerns vis-a-vis the issue of regulation of TB } \\
\text { medicines }\end{array}$ \\
\hline $\begin{array}{l}\text { 9. Opportunities for partnership with private sector, and for strengthening } \\
\text { regulatory processes }\end{array}$ & 9. Key opportunities for partnerships and for quality enhancement \\
\hline $\begin{array}{l}\text { 10. Avenues for institutional development and areas of improvement or new } \\
\text { work }\end{array}$ & 10. Organizational ambitions and plans for future work \\
\hline
\end{tabular}

Abbreviation: TB, tuberculosis.

a Full topic guides are available on request.

the framework of regulation of quality and availability of TB medicines (Figure 1) - namely regulatory authority and capacity; implementation; and efficiency, transparency, and accountability.

India

Background

The Revised National Tuberculosis Control Programme (RNTCP) under the auspices of the Ministry of Health and Family Welfare (MoHFW) of the Government of India had the mandate of prevention and care of TB in the country, including dispensing of medicines through the existing network of government health services. This network included facilities at state, district- and primary-levels, providing TB medicines free of cost. The Central TB Division of the MoHFW is the federal authority responsible for administering the RNTCP at the Centre. The RNTCP officially promulgated the policy of directly observed therapy short-course (DOTS), the WHO-recommended global strategy for TB control, in all government facilities and in affiliated private facilities. Firstline TB medicines for use in government health facilities that implemented the RNTCP were procured centrally (at nationallevel). In the states of Rajasthan and Kerala, the RNTCP was operationalized through the State TB Office which is under the jurisdiction of the state Director of Health Services. The
State TB Officer was assisted by a Chief Medical Officer as well as District TB officers. In both states, free short-course chemotherapy under the DOTS approach was made available through the government's network of health facilities.

India's private pharmaceutical manufacturing sector is one of the largest in the world, valued at $\$ 6.0$ billion, with more than 300 companies. The presence of an informal or illegal sector for manufacture and import of medicines in India is generally acknowledged, although details of volumes are not wellknown. At the time of the study, in the anti-TB drug market, there were 8 major pharmaceutical companies producing single drugs as well as fixed-dose combinations. ${ }^{17}$ There were roughly 65000 distributors and 550000 retail pharmacies in India in $2008 .{ }^{18}$ More than 800000 qualified allopathic doctors work in India in diverse private clinical establishments. Irrational prescriptions of TB drugs in the private sector (including single-drug therapy, inappropriate drugs, and length of regimens), and frequent OTC dispensation of TB medicines have been observed by various researchers. ${ }^{19-22}$ Rajasthan and Kerala, like most other states have numerous private pharmaceutical distributors, wholesalers and retailers, who are either independent, or part of a growing sector of large pharmaceutical franchises. These providers variously obtained their stocks from manufacturers located either in Rajasthan or in other States. No information was available 
on the presence of illicit manufacturers; however, there an informal sector of drug shops was reported in Rajasthan by key informants.

\section{Policy Framework for Regulation of Tuberculosis Medicines} India had no single policy for regulation of TB medicines at the time of undertaking this study, and different organizations and departments of state were responsible for the enforcement of various regulatory norms. In 2013, the Government of India identified 46 drugs, including first line anti-TB medicines, to be included under a new schedule (H1), which specifies that the drugs must be sold on a prescription by qualified medical practitioners and that the pharmacist must maintain a record of the drugs sold, details of the prescribing provider and the name of the patient. Information on the extent of enforcement of schedule $\mathrm{H} 1$ is not available) The Drug and Cosmetics Act defined the mandate of the Central Drugs Standard Control Organization (CDSCO) (the primary regulatory authority for medicines in India), and its subsidiary offices at state-level. At the same time, the RNTCP was administered centrally by the Central TB Division of the MoHFW and was responsible for implementing the DOTS strategy for TB control in all government facilities and affiliated private facilities (NTP, revised schemes for non-governmental organizations [NGOs] and private providers 2008). At the time of the study, all TB medicines in India were schedule $\mathrm{H}$ drugs, which indicates that they are meant to be provided only on prescription by qualified medical practitioners (Interviews NTP official, national-level drug control official; Drugs and Cosmetics Act and Rules 1940, amendment 2005). Neither Rajasthan nor Kerala had a specific policy on regulation of TB medicines. State Drug Controllers' offices were responsible for regulating the sale of all medicines, and the licensing of retail pharmacists and wholesalers.

\section{Regulatory Authority and Capacity}

The CDSCO was mandated to approve new drug formulations, following which manufacturing licenses were obtainable from state-level authorities. TB medicines for use in government and affiliated private facilities that implement the RNTCP were procured centrally (at national-evel). These were either purchased directly or with donor support, or procured by the global drug facility (GDF) of the Stop TB Partnership. At the time of the study, WHO prequalification (PQ) was not a uniform requirement for centralized procurement of $\mathrm{TB}$ medicines, in spite of initiatives on the part of some donors to promote mandatory PQ (Interviews, NTP official, WHO official).

Respondents widely expressed concerns around the technical capacities of national- and state-level regulators. At the time of conducting the study, the CDSCO did not qualify as a "stringent regulatory authority" in accordance with global norms (Interviews, WHO official, NTP official, state-level drug control official, state-level TB control official). WHO officials also expressed concern over variable technical capabilities of different State Drug Controllers. There were also widely expressed concerns around the adequacy of human resource capacity of the national and state regulators (Interviews, national-level drug control official, WHO official). Given over
10000 pharmaceutical manufacturing units in the country, according to a national-level drug control official, regulatory organizations were well short of the prevailing norm of one inspector for every 50 manufacturing units. The CDSCO had reportedly taken steps to check counterfeiting of drugs by increasing the quantum of inspectors, and by instituting formal procedures for prosecution and punitive action against offenders. Amendments in the Drugs and Cosmetics Act to increase criminal penalties for manufacture of spurious drugs and manufacture without licences were also reported to be in progress (Interview, national-level drug control official).

RNTCP norms stipulated the evaluation of drug quality throughout the government drug supply chain, including batch testing prior to release of fresh medicines by manufacturers, and periodic inspection of drug samples at suppliers' premises, drug depots and state and district drug stores (Interviews, NTP official, national-level drug control official). State Drug Control offices are mandated to license retail and wholesale stores and regulate the sale of drugs, including inspecting pharmacies for quality of dispensed drugs and adherence to prescription-drug norms (Interview, national-level drug control official).

Severe human resource shortages were cited as a key obstacle to effective regulation of the retail sector, preventing adherence to a key provision of the Drugs and Cosmetics Act that states that each retailer is required to be inspected at least once a year. A statement by a national-level drug control official reflected the mismatch of capacities and workload - "my 500 inspectors cannot regulate 500000 pharmacies (in the country)." According to officials of the drug control authorities and WHO, reforms were underway to boost the organization's human resource strength. The role of the statutory State Pharmacy Council was largely restricted to registration of trained pharmacists and renewal of their licences, and does not assure the quality of day-today dispensing practices (Interviews, state-level pharmacy council officials).

More than one respondent highlighted the absence of an official body tasked with ensuring the use of particular drug regimens by clinicians (Interviews, WHO official, NTP official, national-level drug control official). The regimens proposed by the RNTCP did not carry weight outside of government facilities, whereas the mandate of the drug regulators is restricted to the registration and approval of specific molecules, not of drug regimens. Statutory professional councils reported that there was no legal framework within which they could correct the prescribing practices of practitioners (Interviews, state-level medical, and pharmacy council officials).

\section{Implementation}

The effectiveness of regulation of production and import of medicines is poorly understood. Press reports had highlighted widespread availability of counterfeit drugs in Indian markets, however, according to informants, studies by the CDSCO and the Indian Medical Association had brought up significantly different figures (lower in the case of the CDSCO study) of the prevalence of counterfeit drugs in the open market (Interviews, national-level drug control officials, state-level medical association officials). Several respondents 
reported that there were no actual instances of penalization of defaulting and illegal manufacturers (Interviews, nationaland state-level NTP officials, state-level medical association officials).

Within the RNTCP, mechanisms to monitor distribution of medicines were widely reported to be stringent. District authorities are responsible for identifying deviations from standard practice and effecting corrections. Transportation of drugs was by independent contract, and security was supported by a system of consignment vouchers. Within government health facilities, it was universally reported that prescribing practices were largely in keeping with DOTS norms (Interviews, national- and state-level NTP officials, WHO official).

Non-adherence to standard treatment regimens by private practitioners and OTC dispensing of TB medicines was widely reported, including by NTP officials and representatives of pharmaceutical companies, to be commonplace and unchecked, confirming several independent research findings. ${ }^{21-23}$ The same respondents highlighted that scheduling norms are also widely violated, with prescription TB medicines available OTC widely and commonly. Reportedly, facility inspections were infrequent and prosecutions rarely took place - many retailers take advantage of this and disregard scheduling norms.

\section{Efficiency, Transparency, and Accountability}

Regulation of prescribing and dispensing practices was marred by a minimal, sometimes conflicted engagement of professional bodies. Representatives of statutory state-level medical and pharmacy councils wholly rejected the possibility of a role for them in controlling deviant provider practices. No pharmacist had ever been struck off the pharmacists' register for infringement of the Indian Pharmacy Act, said a member of a state pharmacy council. The council official appeared to renounce any role in regulation, observing that in spite of widespread infringements of laws by pharmacists, "we do not pressure them." Instead, an educational and informative role of councils was emphasized by this respondent, by way of raising standards and improving practices. There was little by way of professional guidance for private practitioners on best TB treatment practices in line with the International Standards for Tuberculosis Care (ISTC), stated NTP officials. Further, medical associations also actively opposed standardized DOTS regimens on the stated grounds that greater discretion for prescribing practitioners, rather than greater standardization, is preferable for a disease with diverse manifestations (Interviews, state-level medical association officials). Professional councils also appeared isolated from regulatory processes, with most respondents from other regulatory agencies reporting no or little interaction with them (Interviews, national- and state-level drug control officials, NTP officials).

A drug control official narrated recent discussions with WHO officials about their inability to control OTC dispensing of TB medicines: the drug regulatory body is mainly focused on regulating products and equipment, said the respondent, and monitoring pharmacy practices was beyond their capabilities. This respondent also highlighted that drug controllers have no actual authority over medical practitioners or their prescribing practices, including the frequently reported practice of prescribing costlier branded medicines rather than cheaper generics. Drug controllers' almost exclusive focus on ensuring the technical quality of medicines, coupled with the councils' inaction, meant that the key agenda of regulating the practices of dealers and practitioners remains generally unaddressed. The prevalence of TB among rural and poor urban populations made it particularly difficult to regulate $\mathrm{TB}$ medicines, since flourishing, poorly regulated informal drug markets cater to these communities (Interviews, nationallevel drug control official, WHO official).

The division of responsibilities between Central and State authorities was widely reported to be a source of ambiguity and confusion. Rules for approving drug formulations were ambiguously applied, with some companies allegedly obtaining approval illegally from state authorities rather than central authorities (Interview, WHO official, nationallevel drug control official). Several state TB officials were critical of the highly centralized nature of rule-setting around regulatory policies for medicines. A WHO official noted that the decentralization of authority to State drug controllers, with their lower technical capacities, presented a challenge for the maintenance of quality control standards. A drug control official suggested that the task of working with different states, each with their own policies and protocols, was chaotic, and that the implementation of the Drugs and Cosmetics Act was not uniform in different states.

According to a drug control official, regulation of drug availability in India was a complex task involving managing sometimes tacit expectations of different stakeholders -"everyone comes with a motive, the motives are there, but they are seldom talked about." Another drug regulator suggested that it was important to include voices of pharmaceutical manufacturers in the policy-making processes - representatives of manufacturing industry associations are frequently invited to meetings to deliberate policy issues. State TB programme officials cited the role of powerful political influences, and lobbying by pharmaceutical companies to prevent stricter scheduling policies for TB drug availability. A donor representative highlighted that 'political' considerations - the need to protect multiple stakeholder interests and voices - were more pronounced in the domain of pharmaceutical policy than in many other sectors.

\section{Tanzania}

Background

The National Tuberculosis and Leprosy Programme (NTLP), an arm of the MoHFW, was officially charged with prevention and care of TB in the country, including dispensing medicines through their network of health facilities. This network included facilities at provincial-, district- and primary-levels, providing TB medicines free of cost.

Private medical practice in Tanzania was prohibited under socialist rule in $1977,{ }^{24}$ and this law was repealed only in 1991. There was an active private medical sector in urban areas in Tanzania, including a number of larger private forprofit hospitals in the larger cities such as Dar es Salaam and Arusha. Little was known about the profile of the private forprofit sector in rural areas, which is dominated by smaller medical establishments and drug shops. A review by Janovsky 
and Travis indicated that in 2006, there were 900 independent private practices, 339 registered pharmacies, and around 4600 licensed drug shops in the country.

There was little by way of a pharmaceutical manufacturing sector in Tanzania, at the time of the study. All TB medicines in the country were imported by the government, and importation by private distributors was not permitted by law. Government procedure required that the Medical Stores Department (MSD) procure the drugs from WHO-accredited suppliers through international competitive tender. At the time of this study, the GDF of the Stop TB Partnership, hosted by WHO, was active in supporting the Tanzanian NTLP by directly procuring and supplying first-line fixed-dose combination TB medicines (Interviews, WHO and NTLP officials).

Estimates of requirements of TB medicines were made periodically by the NTLP and the MSD, and the medicines were procured. Consignments of medicines were sent to the provincial facilities and distributed to district and primary health facilities (Interviews, Medical Stores officials). At government health facilities and NTP-affiliated private clinics, all TB medicines under the DOTS regimen were required to be prescribed and dispensed free, in keeping with the guidelines of the NTLP.

\section{Policy Framework for Regulation of Tuberculosis Medicines}

Tanzania had an explicit policy aimed at controlling the availability of TB medicines in the country (Manual for Management and Control of Tuberculosis and Leprosy Drugs and Supplies., National TB and Leprosy Programme, Government of Tanzania, 2000). The main elements of the policy were that:

- Importation of $\mathrm{TB}$ medicines into the country is restricted to the Ministry of Health $(\mathrm{MoH})$, through the MSD;

- Only health facilities affiliated with the NTLP are allowed to treat patients for any form of TB.

The original written notice putting the policy into effect was a circular from the MoHSW, and the impetus for this policy was reportedly carried forward and sustained to the present day, with the support of several political actors. The policy of sole procurement of TB medicines by the government was supported by almost all respondents representing different constituencies, including private stakeholders (Interviews, NTP officials, WHO officials, official of association of private health facilities). The inception of private forprofit importation and supply of TB medicines could cause "undesirable influences to impinge on the government supply chain," suggested an official of an association of private health facilities, in defence of the government-only policy.

\section{Regulatory Authority and Capacity}

Government procedure required that the MSD procure TB drugs/medicines from a WHO-accredited supplier through international competitive tender. The Tanzanian Food and Drug Authority (TFDA) was responsible for screening any requests for importation of drugs from local distributors. The TFDA was also responsible for evaluating and registering all pharmaceutical products before they were approved for distribution in the country, for setting norms for prescription drugs, and for licencing pharmacies (Interviews, WHO official, NTP official). Drug control officials reported how the status of their own organization had grown rapidly in the past few years, as a result of strong political will to build regulatory capacity. The country has a growing pharmaceutical manufacturing sector, but at the time of the study, it was reported that there was no or little private manufacture of TB medicines (Interviews, drug control official, medical stores official, owner of private drug distribution company).

The MSD was responsible for the storage and distribution of TB medicines. The NTLP dispensed medicines through the network of government facilities, and also undertakes some partnerships with private providers. In these partnerships, drugs and equipment were provided to private hospitals by the NTLP in exchange for the promise of adherence by the private providers to NTLP guidelines for treatment, case finding, diagnosis, case holding and reporting (Interviews, NTP officials). However, there was no report of a written agreement binding private facilities to adherence to NTLP norms.

While professional regulatory councils such as the Medical Council and the Pharmacy Council are notionally responsible for the conduct of physicians and pharmacists, respectively, most respondents did not perceive that they had a major role in the implementation of this particular policy (Interviews, NTP official, WHO official, drug control official).

\section{Implementation}

The effectiveness of a written policy on restricted importation of TB medicines, backed by strong political commitment was remarked upon by more than one respondent. The policy was widely reported to be faithfully implemented. Most respondents reported that the supply and distribution chain for TB medicines in the public sector was efficiently administered by the MSD, and that there were few concerns apart from occasional interruptions in the stock (Interviews, NTP official, owner of private drug distribution company). Private partners of the NTLP were widely reported to be adherent to NTLP guidelines. TFDA conduct regular supervision and monitoring visits to pharmacies. Occasional infringements with regard to the availability of TB drugs in non-affiliated outlets were noted. Officials admitted significant challenges around the abuse of prescription drugs was common at the point of dispensation, and further, they were unable to cite instances of indictments for the abuse of TB medicines (Interviews, drug control official, WHO official, NTP official).

\section{Efficiency, Transparency, and Accountability}

The image of a well-functioning NTP with a competent human resource network and a steady supply of medicines was emphasized by a number of respondents. The knowledge of readily available free treatment in government facilities may have contributed to a relative lack of interest by private providers to engage more actively with $\mathrm{TB}$ treatment on a for-profit basis. A number of respondents also reported how the strongly vertical nature of administrative decisionmaking and enactment in the TB control programme was a factor in favour of the success of such policies, enabling focused messages and a controlled plan of execution. This 
view was also supported by private stakeholders interviewed (Interviews, official of association of health facilities, WHO official, NTP official, owners of private drug distribution companies).

Private stakeholders were, however, critical of the exclusive nature of NTLP policy deliberations and for seldom involving them in discussions on clinical guidelines, or around policies relating to private sector regulation and partnership (Interviews, managers of private hospitals partnering with NTP, official of association of health facilities). An official of an association of private health facilities warned that private facilities were becoming increasingly cognizant of their financial interests and were organizing to protect these interests.

The other significant challenge to the convention of a vertically controlled programme came from within the government. According to WHO officials, there had recently been significant efforts on the part of MoHSW to integrate the functioning of vertical programmes, including the creation of centralised drug procurement systems. However, independent mandates and funds available to particular programmes such as TB and HIV tended to be an obstacle in complete integration, they said.

Officials also admitted to limited knowledge about the growing, poorly understood informal healthcare markets constituted by drug shops, peddlers and solo clinics - these markets which cater to large, less affluent populations, were believed to be largely out of the reach of government regulators (Interviews, drug control official, NTP official).

\section{Zambia}

Background

The NTLP, an arm of the MoH, was officially charged with prevention and care of TB in the country, including dispensation of medicines through their network of health facilities.

The scale and distribution of the private for-profit medical sector in Zambia was not well-known. Until 1991, healthcare provision was primarily the domain of the public sector. Subsequently policies of economic liberalization permitted the growth of the private medical sector. According to one respondent, an official of the Zambian Medical Association, a majority of Zambian doctors (75\%) still practiced in the public health sector. Several large private corporations were reported to have their own hospitals. According to different respondents, there were approximately 400 private clinics in Lusaka province, the majority of which provided only outpatient services. There was also recognition of a growing role of the non-profit private sector in healthcare in Zambia. At the time of the study, the $\mathrm{MoH}$ was procuring first-line fixed-dose TB medicines from the GDF of the WHO, and also to a lesser extent, independently from representatives of international pharmaceutical companies. All drugs entering the country were required to pass scrutiny by the Pharmaceutical Regulatory Agency (PRA). The $\mathrm{MoH}$ contracted the services of a private company to administer the central medical storage unit.

Estimates of requirements of $\mathrm{TB}$ medicines were made quarterly, based on reports submitted by the NTLP in conjunction with the Pharmaceutical Services Division of the
$\mathrm{MoH}$, and the medicines were procured. Provincial facilities collected their allocations from the medical stores, and the medicines were distributed to district and primary health facilities. At government health facilities and NTP-affiliated private clinics, all TB medicines under the DOTS regimen were required to be prescribed and dispensed free, in keeping with the guidelines of the NTLP.

\section{Policy Framework for Regulation of Tuberculosis Medicines}

At the time of conducting the study, Zambia did not have an explicit written policy specifically for controlling the importation, distribution and dispensation of TB drugs. However, deliberations were underway to formalize a policy requirement restricting the use of all anti-TB medicines to facilities run by and associated with the NTLP only. Regardless, officials of the MoH and the NTLP highlighted the government's commitment to restrict and control TB drug availability, actualized mainly by measures to ensure imports of quality drugs and control dispensing, in partnership with the PRA. TB medicines are required to be dispensed only on prescription by qualified medical practitioners (Interviews, NTP officials, WHO officials).

\section{Regulatory Authority and Capacity}

The steps in regulating importation of medicines included registration, notification, and physical inspection of stocks, by the PRA. In the public sector too, which imports a majority of TB drugs, similar regulatory procedures were followed. The $\mathrm{MoH}$ procured first-line fixed-dose TB medicines from international donors and pharmaceutical companies. All drugs entering the country were required to pass scrutiny by the PRA. The MoH contracted the services of a private company to administer the central medical storage unit, also known as Medical Stores Limited (MSL). The NTLP authorised the prescription and dispensing of TB medicines free at government health facilities and NTP-affiliated private clinics. The mandate of the PRA included regulation of drug manufacture, importation and retail, as well as the licensing and registration of establishments (Interviews, drug control official, NTP official, medical stores official).

The NTLP dispensed medicines through the network of government facilities, and also undertook some partnerships with private providers In these partnerships, drugs and equipment were provided to private hospitals by the NTLP, in exchange for the promise of adherence by the private providers to NTLP guidelines for treatment, case finding, diagnosis, case holding and reporting. At the time of the study, these partnerships were based on informal agreements (Interview, health ministry official).

A key government partner in TB care is the Churches Health Association of Zambia (CHAZ), who have an extensive network of clinics across rural Zambia and receive funds from the government (among other sources) for providing healthcare services, including for TB. CHAZ facilities received government medicines, reported to the public health system, prescribed and dispensed TB medicines according to national guidelines and were supervised in precisely the same way as government units. Furthermore, there was a formal memorandum of understanding guiding their relationship with the NTLP (Interviews, NTP official, CHAZ official). 
Drug control officials expressed grave concerns over financial and personnel shortages limiting their scope of work, particularly in the area of licensing and registration of pharmacy establishments, as well as for regulation of the pharmaceutical retail sector, particularly in the context of concerns over poor dispensing practices in the private forprofit sector. Officials of professional councils stated that they did not have a role in regulating prescribing practices of physicians, and that their role was restricted to oversight of physicians' professional conduct. Lack of human resource capacity was cited by these officials as a major factor inhibiting their effective functioning in this area.

\section{Implementation}

While there is no ban as such on private importation of TB drugs, many respondents were of the view that the private sector's role was limited, even negligible in this area. A PRA official indicated that private import of TB drugs was very limited, since TB medicines had limited market value, further offset by the availability of free TB medicines in the government sector, a view supported by a representative of a major import company. The role of donor support was reported to be critical in sustaining uninterrupted supplies of medicines in the government network of facilities. Some respondents indicated the risks of dependence on donor support in the long run, particularly in the context of rising costs of medicines (Interviews, NTP officials, drug control official).

Many respondents agreed that the supply and distribution chain for TB medicines in the public sector was wellsupervised and administered with few interruptions in the stock. However, regulating private drug distribution was reported as a major challenge by PRA officials, in the context of a growing but poorly understood private pharmacy sector, including many illegal drug shops.

TB progamme managers and provincial officers asserted that prescribing and dispensing practices within government facilities and in affiliated private facilities were well-supervised and there were few instances of non-adherence to national policy guidelines. The affiliated facilities were subjected to supervisory visits and asked to maintain records in the same manner as government clinics. Private providers were also invited to training sessions in TB management, organized by the NTLP. However, several respondents remarked on instances of mismanagement of TB in unaffiliated private sector, and OTC dispensing of TB drugs in pharmacies (Interviews, NTP officials, drug control official).

\section{Efficiency, Transparency, and Accountability}

The role of donor support was reported to be critical in sustaining uninterrupted supplies of medicines. Some respondents indicated the risks of dependence on donor support in the long run, particularly in the context of rising costs of medicines. The success of the NTLP in ensuring adherence to TB guidelines was attributed to a vertically administered programme structure with its own exclusive management units at provincial- and district-levels (Interviews, NTP officials, drug control official). Most private hospitals in partnership with the NTLP were well-appointed institutions with relatively affluent clientele.
Officials reported that solo private healthcare establishments and the informal healthcare sector that were known to cater to less affluent sections, was poorly understood with a largely undocumented set of practices. There were reported to be more than 500 private clinics in Lusaka province, the majority of which provided only outpatient services - many respondents were sceptical of the ability of government regulators to enforce dispensing and prescribing norms in this sector (Interviews, NTP officials, drug control official, medical stores official).

Policy and health system actors' key observations about the processes of regulation of $\mathrm{TB}$ medicines in the three study countries, are summarized in Table 4.

\section{Discussion}

Table 4 highlights the variations and similarities in regulatory processes, and of constraining and enabling factors, between the different countries studied. The existing literature reveals little about the challenges faced by governments, and the opportunities that present, in strengthening regulation of the availability and quality of TB medicines. The dearth of literature on regulatory processes relating to $\mathrm{TB}$ medicines in LMICs made it impossible to couch the findings of these studies in terms of the existing knowledge. Yet the juxtaposition of the differing regulatory processes and factors in the different countries serves to highlight several themes of national as well as cross-cutting relevance. A key limitation of this paper is that its messages derive largely from subjective accounts of the individual actors interviewed, and cannot as such be seen to represent singular objective reality - we attempted to address this limitation by triangulating the observations of study participants with the accounts of other participants, and with relevant policy documentation.

The quality and availability of TB medicines are consequences of regulatory processes that are often hidden from public eye. It is important that these regulatory processes should be accountable, transparent, and in the public interest. To our knowledge, this is the first study to attempt to understand and help strengthen these processes in the context of LMICs. Salient emergent points relating to the three framework elements of regulation (see Figure 1) are discussed below.

\section{Authority and Capacity}

In India, severe problems of financial, human and technical capacity of regulatory bodies, for all regulatory "targets" (see Figure 2: production and procurement, stocking and distribution, prescribing and dispensing), were exacerbated by the absence of a comprehensive policy framework for regulation of $\mathrm{TB}$ medicines. Zambian and Tanzanian authorities too experienced similarly depleted capacities. In the case of Tanzania, this was offset by regulatory authorities feeling relatively empowered, resulting from perceptions of broad political support for their existence and functions, and by well-articulated support for a comprehensive policy for restricting the import, prescibing and dispensing of TB medicines. A notable feature common to all three countries was the lack of engagement of professional (medical and pharmacy) regulatory councils with any activity related to overseeing the prescribing and dispensing practices of the health professionals under their charge. On the positive side 
Table 4. Key Observations About the Regulation of Quality and Availability of TB Medicines ${ }^{\mathrm{a}}$

\begin{tabular}{|c|c|c|c|c|}
\hline India & & Tanzania & Zambia & \\
\hline \multicolumn{5}{|c|}{ Regulatory framework } \\
\hline - & $\begin{array}{l}\text { No comprehensive policy framework for } \\
\text { regulation of TB medicines (-) } \\
\text { Manufacture and import of TB medicines not } \\
\text { specifically restricted } \\
\text { Drugs and Cosmetics Act and MoHFW guidelines } \\
\text { outlined measures to assure quality of procured } \\
\text { medicines (+) }\end{array}$ & $\begin{array}{l}\text { - Policy of MoHSW restricted } \\
\text { imports to government } \\
\text { operators only }(++)^{b}\end{array}$ & $\begin{array}{l}\text { - } \quad \text { Import of TB medicines not } \\
\text { specifically restricted } \\
\text { PRA and MoH guidelines outlined } \\
\text { measures to assure quality of } \\
\text { procured medicines }(+)\end{array}$ & $\begin{array}{l}\text { Production + } \\
\text { procurement }\end{array}$ \\
\hline - & $\begin{array}{l}\text { Drugs and Cosmetics Act (universal) and MoHFW } \\
\text { guidelines (government sector only) outlined } \\
\text { measures to assure norms and standards during } \\
\text { stocking and distribution (+) }\end{array}$ & $\begin{array}{l}\text { MSD and MoHFW } \\
\text { guidelines outlined } \\
\text { measures to assure norms } \\
\text { and standards during } \\
\text { stocking and distribution (+) }\end{array}$ & $\begin{array}{l}\text { PRA and } \mathrm{MoH} \text { guidelines outlined } \\
\text { measures to assure norms and } \\
\text { standards during stocking and } \\
\text { distribution (+) }\end{array}$ & $\begin{array}{l}\text { Stocking + } \\
\text { distribution }\end{array}$ \\
\hline - & $\begin{array}{l}\text { MoHFW mandated DOTS regimens in all } \\
\text { government facilities and in government- } \\
\text { affiliated private facilities (+) } \\
\text { National drug schedules required that TB } \\
\text { medicines be dispensed only on prescription (+) }\end{array}$ & $\begin{array}{l}\text { Policy of MoHSW stated } \\
\text { that only facilities affiliated } \\
\text { to the NTLP were allowed } \\
\text { to prescribe and dispense } \\
\text { TB medicines, in accordance } \\
\text { with DOTS }(++)^{\mathrm{b}}\end{array}$ & $\begin{array}{l}\text { - MoH mandated DOTS regimens } \\
\text { in all government facilities and } \\
\text { in government-affiliated private } \\
\text { facilities (+) } \\
\text { PRA norms required that TB } \\
\text { medicines be dispensed only on } \\
\text { prescription by qualified medical } \\
\text { practitioners (+) }\end{array}$ & $\begin{array}{l}\text { Prescribing + } \\
\text { dispensing }\end{array}$ \\
\hline
\end{tabular}

- Drug controllers faced severe human resource constraints $(--)^{\mathrm{b}}$

- Concerns over technical capacity of central and state regulatory authorities (-)

- $\quad$ Amendments in laws were in process to increase criminal penalties for defaulters $(+)$

- $\quad P Q$ requirement not universal (at time of study) $(-)$

- Drug controllers faced severe human resource constraints $(--)^{\mathrm{b}}$

- Clear lines of authority and perception of fair monitoring capacity in the government TB programme (+)

- Drug controllers faced severe human resource constraints to controlling dispensing practices, had no authority over prescribing practices (-)

- Government recommendations for drug regimens not applicable in private sector $(--)^{\mathrm{b}}$

- $\quad$ Professional councils were uninvolved in matters of regulating practices (-)
- $\quad$ Policy widely supported across constituencies $(++)^{\text {b }}$

- $\quad$ Political support for regulatory body $(++)^{b}$
- Drug controllers faced financial and human resource constraints (-)
Production + procurement
- Clear lines of authority and perception of fair monitoring capacity in the government TB programme $(+)$

- Clear lines of authority and perception of fair monitoring capacity in the government TB programme $(+)$

- Professional councils were uninvolved in matters of regulating practices (-)
- Clear lines of authority and perception of fair monitoring capacity in the government TB programme (+)

Stocking + distribution

- Drug controllers faced financial and human resource constraints (-)

- Clear lines of authority and perception of fair monitoring capacity in the government TB programme (+)

Prescribing + dispensing

- Professional councils were uninvolved in matters of regulating practices (-)

Implementation

- Some concerns over implementation of quality control. Few instances of penal action (-)

- $\quad$ Drug controllers unable to monitor private distribution (--)

- Inspections and prosecutions infrequent, in private sector (-)

- Clear lines of authority and perception of fair monitoring capacity in the government TB programme (+)
- Faithful implementation of import restrictions $(++)^{\mathrm{b}}$

- Clear lines of authority and perception of fair monitoring capacity in the government TB programme (+)
- No specific observations of barriers or enablers

- Clear lines of authority and perception of fair monitoring capacity in the government TB programme

Stocking + distribution

- Drug controllers ability to monitor private distribution questionable (-)
Production + procurement
- $\quad$ Fair adherence to dispensing, prescribing norms in government and affiliated facilities (+)

- $\quad$ Some reports of abuse of prescription-drug norm in private facilities (-)

- Inspections and prosecutions of private

sector defaulters infrequent $(-)$
- Fair adherence to dispensing, prescribing norms in government and affiliated facilities (+)

- Several reports of abuse of prescription-drug norm in private Prescribing + facilities $(--)^{b}$

- Inspections and prosecutions of private sector defaulters infrequent prescribing norms in private facilities $(-)^{b}$
Inspections and prosecutions of private sector defaulters infrequent (-) (-) 
Table 4. Continued.

\begin{tabular}{|c|c|c|c|}
\hline \multicolumn{4}{|l|}{ Efficiency, transparency, and accountability } \\
\hline $\begin{array}{l}\text { - Perceived inefficiencies in coordinating state and } \\
\text { central authorities' roles }(-) \\
\text { Private representation and political involvement } \\
\text { in regulatory affairs widely recognized }(--)^{b}\end{array}$ & $\begin{array}{l}\text { Perceived improved } \\
\text { efficiency resulting from } \\
\text { hierarchical control of TB } \\
\text { programme, and exclusion } \\
\text { of private actors } \\
\text { Perception that efficiency } \\
\text { resulting from hierarchical } \\
\text { control of TB programme, } \\
\text { likely to be attenuated by } \\
\text { moves to integrate disease } \\
\text { programmes (-) }\end{array}$ & $\begin{array}{l}\text { - } \quad \text { Perceived improved efficiency } \\
\text { resulting from hierarchical control } \\
\text { of TB programme } \\
\text { Risk of donor dependence in drug } \\
\text { procurement (-) }\end{array}$ & $\begin{array}{l}\text { Production + } \\
\text { procurement }\end{array}$ \\
\hline $\begin{array}{l}\text { Drug controllers prioritized drug quality } \\
\text { management over regulating distributors and } \\
\text { practitioners (-) } \\
\text { Limited information about distribution networks } \\
\text { among informal/small private sector catering to } \\
\text { poor (-) }\end{array}$ & $\begin{array}{l}\text { Perception that efficiency } \\
\text { resulting from hierarchical } \\
\text { control of TB programme, } \\
\text { likely to be attenuated by } \\
\text { moves to integrate disease } \\
\text { programmes (-) }\end{array}$ & $\begin{array}{l}\text { - Perceived improved efficiency } \\
\text { resulting from hierarchical control } \\
\text { of TB programme }\end{array}$ & $\begin{array}{l}\text { Stocking + } \\
\text { distribution }\end{array}$ \\
\hline $\begin{array}{l}\text { - Professional councils rejected role in regulating } \\
\text { dispensing and prescribing practices }(-) \\
\text { Drug controllers prioritized drug quality } \\
\text { management over regulating distributors and } \\
\text { practitioners }(-) \\
\text { Some professional associations opposed } \\
\text { government regimens }(--)^{\mathrm{b}}\end{array}$ & $\begin{array}{ll}\text { - } & \text { Perceived improved } \\
\text { efficiency resulting from } \\
\text { hierarchical control of TB } \\
\text { programme } \\
\text { Private actors perceived } \\
\text { lack of inclusiveness } \\
\text { of policy-making by TB } \\
\text { programme (-) } \\
\text { Little information about } \\
\text { practices of informal/small } \\
\text { private healthcare providers } \\
(--)^{b}\end{array}$ & $\begin{array}{l}\text { - Perceived improved efficiency } \\
\text { resulting from hierarchical control } \\
\text { of TB programme } \\
\text { Little information about practices of } \\
\text { informal/small private healthcare } \\
\text { providers }(--)^{b}\end{array}$ & $\begin{array}{l}\text { Prescribing + } \\
\text { dispensing }\end{array}$ \\
\hline
\end{tabular}

Abbreviations: MoHFW, Ministry of Health and Family Welfare; TB, tuberculosis; NTLP, National Tuberculosis and Leprosy Programme; PQ, Prequalification; PRA, Pharmaceutical Regulatory Agency; MoH, Ministry of Health; DOTS, directly observed therapy short-course; MSD, Medical Stores Department.

${ }^{a}$ Constraining and enabling factors are tagged with (-) and (+) signs, respectively.

${ }^{\mathrm{b}}$ Most frequent and salient observation.

was a cross-cutting perception of good monitoring capacity and clear lines of authority in the government TB programmes (particularly in the realms of stocking, distribution and prescribing) of each of the three countries.

\section{Implementation}

Implementation challenges abounded, albeit not uniformly across the different countries and for each of the regulatory "targets" (Figure 2). Tanzanian import restriction norms, it was reported, enjoyed political support and consequently were also faithfully implemented. In India, against the backdrop of a massive private pharmaceutical sector, regulators were severely constrained to monitor the quality of stocking and distribution by private operators. Cutting across all three coutnries, reports of fair adherence to dispensing and prescribing norms in government facilities could be contrasted with the non-application of norms - particularly prescribing and dispensing norms - in the private sector. There were several reports of widespread violation of dispensing, prescribing norms in private facilities in all three countries. In the case of India, this supports the findings of numerous studies on the subject, ${ }^{19-22}$ whereas in Tanzania and Zambia there was a relative deficit of formal information around the practices of private providers. In India, it further emerged that the problems of inappropriate prescribing and dispensing were inadequately addressed, since the drug controllers' focus of activities was more on improving the technical quality of medicines, and professional councils were uninvolved in the regulation of day to day practices of healthcare providers.

Efficiency, Transparency, and Accountability

Government TB programmes in all three countries were generally regarded, by government and private stakeholders alike, to be more efficient than other disease programmes in procuring, distributing and dispensing medicines. This efficiency was explained as being associated with hierarchical and centralized control of programme activity, and there were concerns that this efficiency was likely to be reduced by planned integration of discrete disease programmes. A significant proportion of $\mathrm{TB}$ care occured outside of the ambit of the government programme, and the information about private markets for $\mathrm{TB}$ medicines was inadequate, particularly in the Tanzanian and Zambian contexts. These information deficits could present concerns for future TB control efforts, given the contexts of emerging healthcare markets in those countries. In India, ground realities of a dominant private sector posed a complex challenge especially considering the sway of a strong pharmaceutical industry over modestly regulated private dispensers and prescribers. Private interests played a problematic role in many aspects of the regulatory process, from private lobbying around regulation of drug production and procurement, to the actions of private associations in opposing DOTS regimens. The issue of who regulates the behaviour of private actors in the TB market in India is instructive. Even as professional councils rejected a role in regulating dispensing and prescribing practices, drug controllers prioritized the technical chores of drug quality management, over checking the practices of distributors and practitioners. Confusions over the respective roles of state and central drug control authorities in controlling the practices of manufacturers created regulatory gaps and loopholes. The upshot of this collective ambivalence is that regulatory authorities in India had effectively abdicated several key aspects of the regulation of market practices in $\mathrm{TB}$ care. 


\section{Conclusion}

Three critical factors emerge as influencing regulatory processes and performance across all three country case studies - the presence or lack of political and stakeholder support for regulation, inadequate technical and human resource capacity of public regulatory bodies and the nature of private influence on regulatory policy and implementation. These observations have significance for other LMICs.

Political support for regulation of TB medicines is crucial. Tanzanian and Zambian successes in regulating TB medicines are underscored by a written policy (in the case of Tanzania), widespread acceptance of the policy and support of political figures for regulatory organizations. In India conversely, regulation of $\mathrm{TB}$ medicines emerges as a besieged arena, with a fragmented policy and widespread contestation of regulatory policies by private interests. Notwithstanding the institutional support enjoyed by regulatory bodies in Tanzania and Zambia, respondents in all three countries reported significant inadequacies in the technical and human resource capacities of regulatory organizations, explained in part by inadequate funding.

The nature of private influences on regulatory processes is variable and complex. In India, the defining context is of the overwhelming scale and aggressively asserted interests of the private sector, which hamstring the operations of regulatory bodies, and often undermine government efforts to regulate access to TB medicines. In Tanzania and Zambia, where the public sector dominates healthcare provision for diseases such as $\mathrm{TB}$, many private health providers and companies spoke out in support of regulatory policies. Yet there were reports of dissatisfaction with their perceived lack of inclusion in government policy-making, and with restrictions placed on private activity, indicating their growing assertiveness and voice in policy matters.

Strengthening regulation to ensure the quality and availability of TB medicines in LMICs with emerging private markets clearly necessitates greater financial investment in the human and technical capacities of regulatory organizations. In addition to bolstering these tangible capacities, political and ethical transformations are also needed in the way that regulatory organizations are managed and supported to undertake their functions. The example of Tanzania is salutary, and includes a written policy underscoring the social purpose of regulation of $\mathrm{TB}$ medicines, and political endorsement for regulatory organizations. India would be well-served by similar expressions of political support for regulation of the quality and availability of TB medicines - the recent step of application of schedule $\mathrm{H} 1$ to TB drugs represents a critical advance in this direction. Finally, it is critical that regulatory organizations be insulated from and empowered to resist the influence of private vested interests, in the process of making and implementing regulatory policies.

\section{Acknowledgements}

We are grateful to NTP and WHO country offices of each of the three countries - India, Tanzania, and Zambia for their support, assistance and advice in undertaking the country case studies. The Indian arm of the study was undertaken with valuable contributions from Maulik Chokshi, Anjali Singh, Sunil George, and Namrata Verma. We are also grateful for extensive comments on the manuscript provided by Knut Lonnroth, William Wells, Christian Lienhardt, and Diana Weil. Funding for this work was received from USAID's TBCARE programme. All views expressed are those of the authors and not necessarily of their organizations or organizational sponsors.

\section{Ethical issues}

Ethical clearance for the Indian case study was obtained from the institutional ethics committee of the Public Health Foundation of India, Gurgaon, India.

\section{Competing interests}

$\mathrm{MU}$ is a staff member of the WHO, Geneva, Switzerland. The views expressed in this publication do not represent the decisions or policies of WHO.

\section{Authors' contributions}

KS led the conduct of the case studies from which the material for this manuscript is drawn, including study design, data collection, and analysis. KS prepared the draft manuscript and revised successive versions. MU provided extensive comments and direct inputs on successive drafts.

\section{Authors' affiliations}

${ }^{1}$ Public Health Foundation of India, Gurgaon, India. ${ }^{2}$ Global TB Programme, World Health Organization, Geneva, Switzerland.

\section{References}

1. Ratanawijitrasin S, Wondemagegnehu E. Effective Drug Regulation: A Multicountry Study. Geneva: World Health Organization; 2002.

2. Management Sciences for Health (MSH). Improving Drug Management to Control Tuberculosis. Manager. 2001;10(4):122.

3. Maalaoui N. Strengthening TB Drug Management in the Sudanese National TB Control Program: In-Depth Review of TB Drug Management. Khartoum; 2009.

4. Vermund SH, Altaf A, Samo RN, et al. Tuberculosis in Pakistan: A decade of progress, a future of challenge. J Pak Med Assoc. 2009;59(4):1-8.

5. Lönnroth K, Castro KG, Chakaya JM, et al. Tuberculosis control and elimination 2010-50: cure, care, and social development. Lancet. 2010;375(9728):1814-1829. doi:10.1016/s01406736(10)60483-7

6. Lönnroth K, Uplekar M, Arora VK, et al. Public-private mix for DOTS implementation: what makes it work? Bull World Health Organ. 2004;82(8):580-586.

7. Uplekar M. Involving private health care providers in delivery of TB care: global strategy. Tuberculosis (Edinb). 2003;83(13):156-164

8. Wondemagegnehu E. Counterfeit and Substandard Drugs in Myanmar and Viet Nam. Geneva: World Health Organization; 1999. http://apps.who.int/medicinedocs/pdf/s2276e/s2276e.pdf. Accessed December 17, 2014.

9. Barrett S, Fudge C. Policy and Action: Essays on the Implementation of Public Policy. London: Methuen; 1981.

10. Hjern B, Hull C. Implementation Research as Empirical Constitutionalism. Eur J Polit Res. 1982;10(2):105-115. doi:10.1111/j.1475-6765.1982.tb00011.x

11. Gilson L, Hanson K, Sheikh K, Agyepong IA, Ssengooba F, Bennett S. Building the field of health policy and systems research: social science matters. PLoS Med. 2011;8(8):e1001079. doi:10.1371/ journal.pmed.1001079

12. Sheikh K. Experiences of Regulating and Restricting the Availability of TB Medicines in Tanzania and Zambia. Geneva: World Health Organization; 2009.

13. Sheikh K, Singh A, Chokshi M, George SM. Regulating the Availability of TB Medicines in India - a Policy Process Appraisal. 
Public Health Foundation of India; 2011.

14. Patton MQ. Qualitative Research and Evaluation Methods. London: SAGE; 2002.

15. Silverman D. Qualitative Research: Theory, Method and Practice. Sage Publications Inc; 2004.

16. Ritchie J, Spencer L. Qualitative data analysis for applied policy research. In: Burgess RG, Bryman A, eds. Analyzing Qualitative Data. London: Routledge; 1994:173-194.

17. Catalani E. Review of the Indian market of anti-tuberculosis drugs: focus on the utilisation of rifampicin-based products. Int $J$ Tuberc Lung Dis. 1999;3(11s3):S289-S291.

18. Langer E, KelkarA. Pharmaceutical Distribution in India. Biopharm International website. http://www.biopharminternational.com/. Accessed December 17, 2014. Published 2008.

19. Uplekar M, Shepard D. Treatment of tuberculosis by private general practitioners in India. Tubercle. 1991;72(4):284-290. doi:10.1016/0041-3879(91)90055-w

20. Singla N, Sharma P, Singla R, Jain R. Survey of knowledge, attitudes and practices for tuberculosis among general practitioners in Delhi, India. Int J Tuberc Lung Dis. 1998;2(5):384389.

21. Uplekar M, Juvekar S, Morankar S, Rangan S, Nunn P. Tuberculosis patients and practitioners in private clinics in India. Int J Tuberc Lung Dis. 1998;2(4):324-329.

22. Udwadia ZF, Pinto LM, \& Uplekar MW. Tuberculosis management by private practitioners in Mumbai, India: has anything changed in two decades? PloS One. 2010;5(8):e12023. doi:10.1371/ journal.pone.0012023

23. Prasad R, Nautiyal RG, Mukherji PK, Jain A, Singh K, Ahuja RC. Treatment of new pulmonary tuberculosis patients: what do allopathic doctors do in India? Int $J$ Tuberc Lung Dis. 2002;6(10):895-902.

24. Janovsky K, Travis P. Non-state Providers of Health Care in Tanzania: Governance, stewardship and international support. Report for WHO; 2006 